STRUCTURAL SCIENCE CRYSTAL ENGINEERING MATERIALS

ISSN 2052-5206

\section{Understanding exceptional polymorphs}

\author{
Jonathan W. Steed*
}

Department of Chemistry, Durham University, South Road, Durham DH1 3LE, UK. *Correspondence e-mail: jon.steed@durham.ac.uk

In an engaging and thoughtful article in this issue Carol Brock (Brock, 2016) of the University of Kentucky puts forward a typically insightful, modestly understated and detailed analysis of some of the organizing principles behind crystal structures with high $Z^{\prime}$. Did I lose your interest already? It sounds obscure doesn't it? Some crystallographic parameter ... a few odd, niche structures. Who cares, right? Wrong! Let me tell you why. Of course you already know what $Z^{\prime}$ is; loosely the number of symmetry-independent molecules in the asymmetric unit. As an Acta $B$ reader you also know just how extraordinarily important the organic/molecular solid state is. The understanding and control of solid forms in general is the Holy Grail of structural scientists. Industry, particularly pharma and agrichem, cares enormously about the solid form of molecules. The solid form impinges directly on solubility, bioavailability, processing characteristics, bulk density, dissolution rate, permeability, surface electrostatic charge and so on (Brittain, 1999). It is all true. All that background justification you have been reading in grant applications for so long. Moreover, understanding and even predicting crystal structure is one of the grand fundamental challenges in science. So any step forward in that direction is extremely important.

What do I mean by solid form exactly? It is a catch-all phrase that encompasses the science of polymorphism, co-crystals, solvates and perhaps salt form. There is no doubt that polymorphism and co-crystal formation are extremely hot topics at present. There has been all sorts of excitement about the FDA classification of co-crystals as being akin to new polymorphs of active pharmaceutical ingredients (US Department of Health and Human Services, 2016) and of course the burgeoning number of litigations concerning polymorphism ever since the original Zantac case (Bernstein, 2002) speaks to their commercial importance. But, where does $Z^{\prime}$ fit in? In effect the understanding of structures with $Z^{\prime}>1$ is equivalent to the understanding of polymorphism itself. The phenomenon is also related to the understanding of co-crystals since a structure with $Z^{\prime}=$ 2 has two symmetry-independent molecules and so does a binary co-crystal (with $Z^{\prime}=1$ ). In terms of crystallographic symmetry, and for that matter computational complexity, the two situations are conceptually related. A holistic understanding of polymorphism, cocrystal formation and structures with multiple symmetry-independent molecules go hand-in-hand with one another (Steed \& Steed, 2015). Indeed it is a fact that compounds that crystallize with $Z^{\prime}>1$ also have a tendency to form co-crystals (Anderson $e t$ al., 2009).

It has gradually become clear that the simple $Z$ ' parameter is a 'catch all' description of a variety of phenomena with diverse causes. As many crystallographers have noted, however, the presence of many symmetry-independent molecules in a structure is a sure sign that something interesting is going on. Perhaps if we can understand these 'exceptions' (less than $10 \%$ of structures in the CSD are $Z^{\prime}>1$; Steed \& Steed, 2015) we may move a little closer to addressing the bigger problem of understanding the molecular solid state in general. After all, who could fail to be impressed and intrigued by the new high $Z^{\prime}$ world record holder, the eightfold polycatenated structure of 1,3,5-tris(4carboxyphenyl)benzene with $Z^{\prime}=56$ (Fig. 1; Zentner et al., 2015).

Carol Brock has been interested in the underlying principles of crystal packing for a very long time. Her 1994 review co-authored with Jack Dunitz entitled 'Towards a grammar of crystal packing' laid out some rigorous principles that have stood the test of time (Brock \& Dunitz, 1994). In that same year she also pointed out the first well argued chemical-structure-based explanation for the occurrence of high $Z^{\prime}$, pointing out that monoalcohols, depending on the steric constraints of the substituent and the need to 


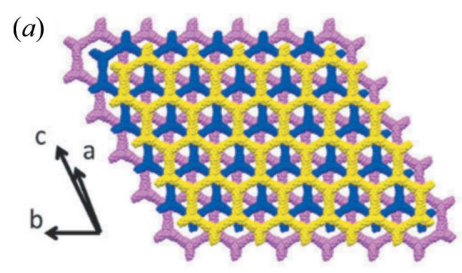

(b)

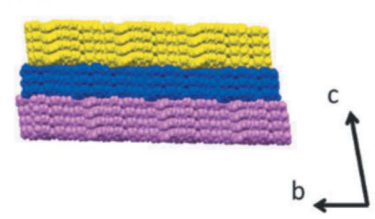

(c)
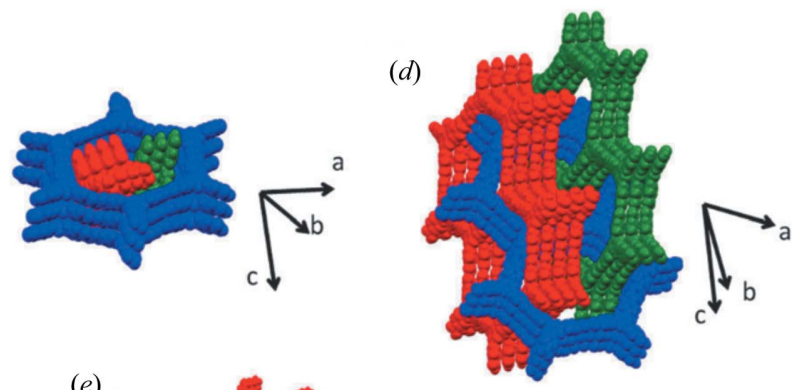

(e)

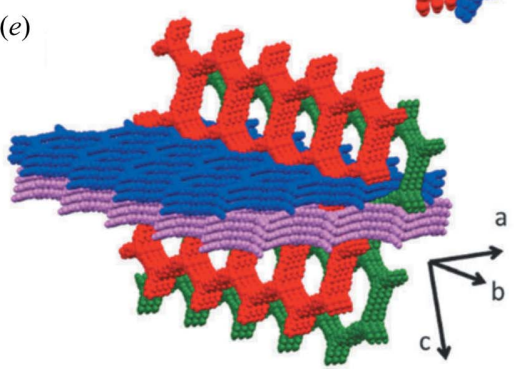

Figure 1

Crystal structure of the $Z^{\prime}=56$ polymorph of 1,3,5-tris(4-carboxyphenyl)benzene: $(a)$ overhead view of the hexagonal sheets, shifted in respect to each other; (b) $\pi$-stacks of hexagonal sheets with thickness of alternating 3 and 4 molecules; $(c) 7$ molecules fit within the hexagons; $(d)$ eightfold polycatenation; $(e)$ extended view of the eightfold polycatenation of hexagonal layers (reproduced with permission from Zentner et al., 2015, (C) Royal Society of Chemistry).

maintain $\mathrm{OH} \cdots \mathrm{O}$ hydrogen bonding, either had to adopt high-symmetry space groups or high $Z^{\prime}$ structures (Brock \& Duncan, 1994). Since that time it is probably fair to say that she has thought long and hard about the issues surrounding multiple symmetry-independent molecules in crystal structures. Her work on the incommensurately modulated 2chlorobenzo-1,3,2-dithiarsole (Bakus II et al., 2013) showed just how extraordinarily challenging the technical aspects of the crystallography can become, leading even her to comment that 'the amount of time necessary to refine and interpret a modulated structure is great enough that it may often seem wiser just to publish a disordered structure in the basic cell'. However, as one of the few people who is capable of spending the 'amount of time necessary', she went on in that same paper to conclude that if the goal is to understand a complicated structure then there is no substitute for time spent looking at it carefully with a powerful display program'. It seems that she has now gone on to do just that for every well defined organic structure in the CSD with $Z^{\prime}>4$; all 284 of them. In fact, each structure has been 'considered in detail at least three times over a period of several years'. The results of this impressive and painstaking study are published in this issue. The conclusions that she draws from this detailed study are not a smoking gun for the explanation of high $Z^{\prime}$ behaviour. Rather, they illustrate that the high $Z^{\prime}$ phenomenon, like polymorphism itself, has many root causes. However, careful study of each structure allows the identification of organizing principles for almost all of them. Some of Brock's key generalizations include the following:

many structures are modulated in a simple way or contain asymmetric hydrogen-bonded aggregates;

molecules are often related by a pseudotranslation that would be a crystallographic translation but for small molecular displacements and rotations;

in the majority of structures there are aggregates (e.g. oligomers, columns or layers) held together by strong intermolecular interactions with approximate local symmetry;

many structures have several features that combine to give the high $Z^{\prime}$ value;

the number of different molecular conformations is usually small;

some structures have more exotic packing features, such as ordered faults and alternating layers of different types.

Even these modest generalizations do not account for every case and Brock leaves the door open for future research saying 'a very few structures are so complex that it is difficult to understand how the crystals could have formed'. This new comprehensive survey, in conjunction with a groundswell of work by a number of groups on this increasingly intriguing problem over the past 20 years, shows that there is no onesize-fits-all explanation and that the details of each structure are uniquely tied to the chemical details of the molecules that comprise it. The search goes on, but perhaps we are now at least beginning to know how to formulate the question!

\section{References}

Anderson, K. M., Probert, M. R., Whiteley, C. N., Rowland, A. M., Goeta, A. E. \& Steed, J. W. (2009). Cryst. Growth. Des. 9, 10821087.

Bakus II, R. C., Atwood, D. A., Parkin, S., Brock, C. P. \& Petricek, V. (2013). Acta Cryst. B69, 496-508.

Bernstein, J. (2002). Polymorphism in Molecular Crystals. Oxford: Clarendon Press.

Brittain, H. G. (1999). Editor. Polymorphism in Pharmaceutical Solids, 1st ed. New York: Marcel Dekker Inc.

Brock, C. P. (2016). Acta Cryst. B72, 807-821.

Brock, C. P. \& Duncan, L. L. (1994). Chem. Mater. 6, 1307-1312.

Brock, C. P. \& Dunitz, J. D. (1994). Chem. Mater. 6, 1118-1127.

Steed, K. M. \& Steed, J. W. (2015). Chem. Rev. 115, 2895-2933.

US Department of Health \& Human Services, Food \& Drug Administration Center for Drug Evaluation \& Research (CDER) (2016). Regulatory Classification of Pharmaceutical Co-Crystals Guidance for Industry, http://www.fda.gov/ucm/groups/fdagovpublic/@fdagov-drugs-Gen/documents/document/ucm516813.pdf.

Zentner, C. A., Lai, H. W. H., Greenfield, J. T., Wiscons, R. A., Zeller, M., Campana, C. F., Talu, O., FitzGerald, S. A. \& Rowsell, J. L. C. (2015). Chem. Commun. 51, 11642-11645. 